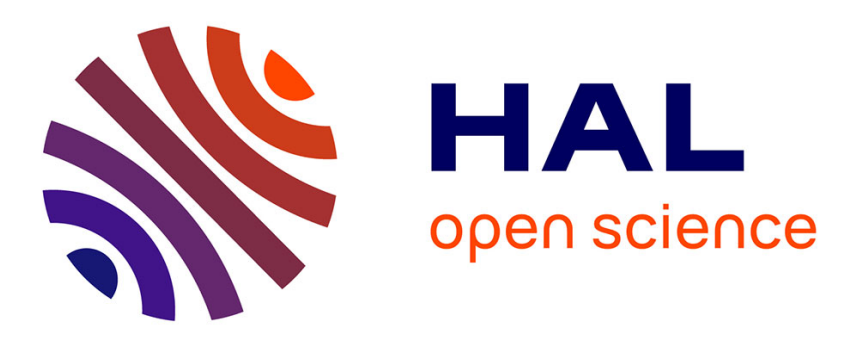

\title{
Group behaviours and individual spatial sorting before departure predict the dynamic of collective movements in horses
}

Léa Briard, Jean-Louis Deneubourg, Odile Petit

\section{To cite this version:}

Léa Briard, Jean-Louis Deneubourg, Odile Petit. Group behaviours and individual spatial sorting before departure predict the dynamic of collective movements in horses. Animal Behaviour, 2021, 174, pp.115-125. 10.1016/j.anbehav.2021.01.014 . hal-03027357

\section{HAL Id: hal-03027357 \\ https://hal.science/hal-03027357}

Submitted on 27 Nov 2020

HAL is a multi-disciplinary open access archive for the deposit and dissemination of scientific research documents, whether they are published or not. The documents may come from teaching and research institutions in France or abroad, or from public or private research centers.
L'archive ouverte pluridisciplinaire HAL, est destinée au dépôt et à la diffusion de documents scientifiques de niveau recherche, publiés ou non, émanant des établissements d'enseignement et de recherche français ou étrangers, des laboratoires publics ou privés. 


\section{Group behaviours and individual spatial sorting before departure predict the dynamic of collective movements in horses}

Léa BRIARD ${ }^{1}$, Jean-Louis DENEUBOURG ${ }^{2}$ \& Odile PETIT $^{3}$

${ }^{1}$ Research Centre on Animal Cognition (CRCA), Centre for Integrative Biology (CBI), Toulouse University, CNRS, UPS, Toulouse 31062, France.

${ }^{2}$ Faculty of Sciences, Université Libre de Bruxelles, Bruxelles, Belgique

${ }^{3}$ Cognitive and Social Ethology group, PRC, UMR 7247, CNRS, INRAe, Université de Tours, IFCE, 37380 - Nouzilly, France.

Corresponding author: Léa Briard

Correspondence:

Léa Briard - drleabriard@gmail.com

Research Centre on Animal Cognition (CRCA - CBI), UMR 5169, CNRS

Door 220, Bat 4R3,

Université Paul Sabatier

118 route de Narbonne

31062 TOULOUSE, FRANCE

Word count: 8093 


\section{INTRODUCTION}

Animals that live in groups face the daily challenge to decide where and when the group should move. By moving together, they maintain group cohesiveness which brings them several advantages: protection from predators, information about feeding sites, resources defence (Alexander 1974; Danchin et al. 2008). Therefore, group members need to seek a consensus by making a decision collectively. Consensus decision can be either shared or unshared (Conradt \& Roper, 2005). In shared consensus decision, all group members contribute to the decision outcome, either equally (regardless of individual characteristics) or partially (some individuals have a greater influence, Pyritz et al. 2011). In unshared consensus, one particular individual decides systematically where and when the group should go. It is, however, more interesting to consider a spectrum from shared consensus to unshared consensus rather than a binary distinction.

In the study of mechanisms underlying such collective decisions, a frequent approach is to identify the type of consensus by seeking for individuals that could play a key role during decision-making processes (Petit, Gautrais, Leca, Theraulaz, \& Deneubourg, 2009). Specific individuals, either old, high-ranking or of a specific sex, have been reported to occupy the position of leaders in various species (King, Douglas, Huchard, Isaac, \& Cowlishaw, 2008; Schaller, 1963). However, there are as many studies, if not more, that found that leadership is rather distributed among group members (King et al. 2009; Petit \& Bon 2010). Moreover, what one calls a leader is usually the individual that took the vanguard position during collective movements although there is no evidence that this individual decided for others (Bourjade, Thierry, Hausberger, \& Petit, 2015). For instance, in one of the most cited examples of despotic leadership (i.e. unshared consensus decision), the dominant male in mountain gorillas (Gorilla gorilla berengei: Schaller 1963), the departure of the silverback has been reported to be preceded by grunts emitted by other group members 
suggesting a rather shared decisional process (Stewart \& Harcourt, 1994). However, this requires looking beyond the time of departure as decision-making processes may occur beforehand and the influence of all group members measured.

Indeed, studies on collective movements rarely took into account the events preceding collective movements. However, the arousal state, or "mood" (Ward \& Zahavi, 1973), of individuals may influence the dynamic of the impending collective movements in terms of number of participants or joining duration. For instance, group dispersion has been shown to influence the number of participants in mammals (white-faced capuchin, Cebus capucinus: Leca, Gunst, Thierry, \& Petit, 2003; Tonkean macaque, Macaca tonkeana and rhesus macaque, Macaca mulatta: Sueur \& Petit, 2008; sheep, Ovis aries and cattle, Bos taurus: Ramseyer, Boissy, Dumont, \& Thierry, 2009; Ramseyer, Thierry, Boissy, \& Dumont, 2009; European bison, Bison bonasus: Ramos, Petit, Longour, Pasquaretta, \& Sueur, 2015) and birds (black-headed gulls, Larus ridibundus: de Schutter 1997; domestic goose, Anser anser: Ramseyer et al. 2008), fish (Damselfish, Dascyllus aruanus: Ward et al. 2013). Some individuals can also display behaviour that indicates their motivation to move, for instance by moving away from group members in the desired direction (Hamadryas baboon, Papio $h$. hamadryas, Kummer 1968). In domestic geese, sheep, cattle and bison, the number of participants increased with the number of individuals heading in the direction of the movement (Ramseyer et al. 2008; Ramseyer, Boissy, Dumont, \& Thierry, 2009; Ramseyer, Thierry, Boissy, \& Dumont, 2009; Ramos et al. 2015). In some species, this number increased with the number of vocalizers (meerkat, Suricata suricatta: Bousquet et al. 2011; African elephant, Loxodonta Africana: O'Connell-Rodwell et al. 2012; African wild dog, Lycaon pictus: Walker et al. 2017; red-fronted lemur, Eulemur rufifrons: Sperber et al. 2019). In several species of primates, the number of individuals moving on few meters towards a specific direction before departure influenced the final decision of the group (Kummer, 
1968a; Seltmann, Majolo, Schülke, \& Ostner, 2013; Strandburg-Peshkin, Farine, Couzin, \& Crofoot, 2015; Sueur, Deneubourg, \& Petit, 2010).

Such predeparture behaviours have been viewed as a preparation for collective movements (Ramseyer, Boissy, Dumont, et al., 2009). However, to be valid, this assumption must be tested by at least verifying that the observed behaviours are specific to the context of collective movements. One solution, for instance, is to compare predeparture behavioural patterns with behavioural patterns exhibited during control periods that did not precede a collective movement. Such method is commonly used in studies on the function of postconflict behaviours that compare matched-control periods with post-conflict periods to deem the observed behavioural pattern, a reconciliation process (e.g. white-face capuchins: Leca, Fornasieri, \& Petit, 2002; domestic horses: Cozzi, Sighieri, Gazzano, Nicol, \& Baragli, 2010). However, so far, such an approach has never been used in the context of collective movements and predeparture behaviours. In this study, we applied it to this context using domestic horses, Equus ferus caballus, as a model.

Horses are highly-social species that form long-lasting bonds (Waring, 2003). Distributed leadership has been reported with an influence of individual characteristics (age: Tyler, 1972; dominance rank: Krueger, Flauger, Farmer, \& Hemelrijk, 2014; personality: Briard, Dorn, \& Petit, 2015). However, in both Przewalski (Equus f. przewalskii, Bourjade et al. 2015) and domestic horses (Briard et al 2015; Briard et al. 2017), the characteristics of the initiator did not explain variation in recruitment success (e.g. number of followers or joining speed). Moreover, predeparture behaviours such as moving away from the group or maintaining a peripheral position occur in Przewalski horses (Bourjade et al. 2009, 2015) and may indicate negotiation processes due to higher conflict of interests as they correlate with longer recruitment phase (Bourjade et al., 2009). In such a context, exploring the predeparture period appears necessary to understand the collective decision-making of horses. This study 
aimed to investigate whether: (1) predeparture behaviours can be observed in domestic horses and if so, whether the observed behavioural patterns (2) are specific to the context of collective movements by comparing them to control periods and (3) can explain the dynamic of ensuing collective movements. Based on previous studies in Przewalski horses (Bourjade et al. 2015) and other ungulates (e.g. Ramseyer, Boissy, Dumont, \& Thierry, 2009; Ramseyer, Thierry, Boissy, \& Dumont, 2009), we expect to see, as departure gets closer, an increase in the arousal of the group. This could manifest itself through an increase in activity, a decrease in group dispersion or the alignment of group members towards the direction of the future collective movement. If such behavioural patterns exist and are specific to predeparture periods, we do not expect to observe them in control periods. However, if we do not find any differences between predeparture and control periods, then predeparture behaviours cannot be deemed as preparatory (i.e. an anticipation of a future collective movement).

\section{MATERIAL AND METHODS}

\section{Animals and Environment}

The focal groups were bred at La Ferme de Bonjacques, a horse husbandry located in eastern France $\left(48^{\circ} 06^{\prime} 00.0^{\prime \prime} \mathrm{N}, 6^{\circ} 06^{\prime} 01.0^{\prime \prime} \mathrm{E}, 305 \mathrm{~m}\right)$. Both groups were composed of 9 mares of various breeds aged from 9 to 28 years old for group 1 and 3 to 22 years old for group 2 (see SI Appendix A for more details). All horses were individually recognisable by their morphology, coat colours and white markings. Both groups were kept on hilly pastures (group 1: 8 ha, group 2: 11 ha) composed of large grassland areas with vegetation forming natural, shaded shelters. Due to the relief and the vegetation, individuals were never able to see the entire pasture from any given point. A river, allowing individuals to have free access to water crossed both pastures increasing the number of distinct zones. Both groups had access to a salt lick stone and group 1 had access to a hayrack $(2 \times 2 \mathrm{~m})$ but spent less than $10 \%$ of the total 
101 observation period eating from it. Both groups had been accustomed to human presence during a preliminary observation month.

\section{Observation Procedure}

Groups were observed and filmed for about two months for a total of 184 hrs for group 1 and 112 hrs for group 2. Two observers approached horses on foot up to a maximal distance of about $20 \mathrm{~m}$ and used handheld two-way radios to communicate when separated. Each of them had a camera to ensure that the entire group was continuously filmed. Over the sampling (Altmann, 1974) the position of every individual using a pair of telemetric binoculars (precision: $1 \mathrm{~m}$ ) and a compass (precision: $1^{\circ}$ ). The observer stayed still throughout the scan and attributed for each horse a distance in meter (horse-observer distance) and an angle in degree by pointing the compass towards each horse and placing the orienting arrow on the magnetic needle to read the value. During those scans, the observer also recorded the activity (inactive: at rest - standing with a flexed foot or recumbent- or active: all other activities) and the orientation of each individual according to four noticeable and fixed points in the environment at $90^{\circ}$ or $180^{\circ}$ of one another.

\section{Data Scoring}

Two persons watched the videos and recorded the identity and the behaviour of every

121 individual initiating or joining a collective movement. Before they could score different

122 videos, we ensured inter-observer concordance by asking them to score the same videos and 123 comparing their results until they reached 95\% concordance (Caro, Roper, Young, \& Dank, 1979). 
Initiation and joining latencies

Departure was defined by the movement of an initiator, that is, any individual that first travels at least $20 \mathrm{~m}$ in less than $20 \mathrm{~s}$ outside the group without pausing and with its neck kept above the horizontal position (Bourjade et al., 2009; Briard et al., 2015). Then, any horse moving away from the group with its neck kept above the horizontal position and in the same direction as the initiator was identified as a follower. For each follower, we defined a joining latency by calculating the time between an initiation and the moment an individual joined it (i.e. first step taken in the same direction as the initiator). Using these latencies, we determined the joining rank of individuals for each collective movement (i.e. from 1, the initiator, to 9, the last follower). A collective movement begins with a start attempt and ends with the arrival of the last follower (Petit and Bon 2010; Briard et al. 2015). We defined the goal area as sites in which all animals stopped walking and started a new activity such as foraging or resting. We defined a predeparture period as those corresponding to the period between the end of the preceding collective movement and the initiation of the focal movement. However, we decided to stop only up to 60 minutes before departure because the sample size for more distant scans was too small (less than 5 events per group). We recorded for group 1 and 2, 56 and 73 initiations respectively, 43 and 50 of them involving the entire group and with all individuals always visible from 60 minutes before initiation to the end of the collective movement. So, the analysis focused on these 43 and 50 events.

\section{Group behaviour before departure}

During these 60 minutes preceding initiation, we measured five different group behaviours using scans performed every 5 minutes: number of inactive individuals, number of goal-oriented individuals, distance to goal area, dispersion, and density at the front of the group (see Table 1 for definitions). Since initiation is relatively unpredictable, we never had a 
scan of the group performed at the exact moment the initiator started to move. Therefore, the scans at $0 \mathrm{~min}$ (i.e. first step of the initiator) were completed using video recordings. Then, preceding scans obtained from direct observation were categorized into half-open 5-min time intervals (e.g. ]0-5min], ]5-10min], etc.). From angle and distances values obtained by instantaneous scan sampling using the telemetric binoculars and the compass, we were able to calculate individual xy-coordinates: $X_{i}=\cos \left(\alpha_{i}\right) \times d_{i}$ and $Y_{i}=\sin \left(\alpha_{i}\right) \times d_{i}$ with $\alpha_{i}$ the angle in radian and $d_{i}$ the distance in meters. Since the goal area could not be anticipated, we defined its angle and distance every 5 minutes based on the video recordings, the individual angle and distance of the focal scan and a cadastral plan of the pasture. The xy-coordinates of the group barycenter were equal to the mean of individual xy-coordinates, $X_{b c}=\sum x_{i} / N$, and $Y_{b c}=\sum y_{i} / N$, with $N=9$. The index of group dispersion was equal to the squared deviations from the barycenter divided by $N, D=\sum \sqrt{ }\left[\left(X_{i}-X_{b c}\right)^{2}+\left(Y_{i}-Y_{b c}\right)^{2}\right] / N$. Finally, with a similar formula $D_{i a}=\sqrt{ }\left[\left(X_{i}-Y_{a}\right)^{2}+\left(X_{i}-Y_{a}\right)^{2}\right]$ with $X_{a}$ and $Y_{a}$ the xy-coordinates of the goal area, we calculated individual distances to the goal area and attributed a topological rank based on topological distances (i.e. rank 1 is attributed to the closest individual). The front of the group was determined using the closest individual to the goal area as a referential. The density at the front of the group was calculated using the number of individuals within a 10-meters radius around the referential.

\section{Statistical analysis}

The effect of time on the five different group behaviours was investigated using Linear Mixed-Effects Models for dispersion (after a log-transformation due to a right-skewed distribution) and distance to goal area (LMM, R package nlme v. 3.1-140, Pinheiro et al. 2020) or Generalized Linear Mixed-Models with a Poisson distribution for group activity, orientation and front density (glmmPQL R package MASS v7.3-51.4, Venables \& Ripley 
2002). Given the relationship between the distance to goal area and time, we used a quadratic

177 fit $\left(y \sim x+I\left(x^{2}\right)\right)$. Finally, we used as a random factor the identity of each collective movement

178

179 nested within the group identity and added a correlation structure (corAR1) to take into account the sequential dependence of observations.

To assess if group behaviour could predict the imminence of a collective movement, we compared the predeparture periods with control periods. These control periods were taken off scans performed at least 60 minutes away from any collective movements. We only used 5 time categories (from 0 to 60 min before departure, with 15 -min intervals) to ensure sufficient sample size per time category $\left(N_{0}=101, N_{15}=103, N_{30}=104, N_{45}=92, N_{60}=70\right)$. Since there is no initiation to be used as a referential, we randomly assigned a fifth of the scans to the time category $0 \mathrm{~min}$. Then, based on their timing, preceding scans were assigned to one of the four remaining time categories, i.e. [15-10[, [30-25[, [45-40[ or [60-55[ min before category $0 \mathrm{~min}$. Isolated scans, that could not be connected to a time category $0 \mathrm{~min}$, were discarded. For orientation, because we did not have any referential direction for the control periods, we used the direction adopted by the majority in each time category $0 \mathrm{~min}$ to then look at the number of individuals that had adopted this direction over the previous time categories (i.e. from $10 \mathrm{~min}$ to $60 \mathrm{~min}$ before). Finally, since front density and group distance to the goal area were measures that rely on the existence of a goal area, they were not compared to control periods. We compared the effect of time on these three behaviours during control periods using similar models than for the predeparture period (see above for details). As independent variables, we used time (from 0 to $60 \mathrm{~min}$ before departure) with an interaction with a binary variable called period type $(0=$ predeparture; $1=$ control $)$.

To assess the influence of predeparture behaviours on the dynamic of the collective movements (i.e. the speed and joining order), we conducted two types of analyses. For the duration of the joining phase, we used a linear mixed-effect model (LMM) with the five group 
201 behaviours as independent factors (i.e. dispersion, density, activity, orientation and distance to 202 the goal area; Table 1) and the log-transformed latency of the last follower as the dependent 203 variable (continuous data with a right-skewed distribution). Dispersion and density at the 204 front were log-transformed to linearize their relationship with the dependent variable and 205 facilitate the interpretation of the model's coefficients. We tested this model at 3 different 206 moments: at initiation, 25-30 $\mathrm{min}$ and 55-60 min before departure. We used the multimodel 207 inference method (R package MuMIn v.1.43.6; Barton 2019) to determine which candidate model best explained the dynamic of the joining phase. Models were first compared according to their Akaike's information criterion (AIC) corrected for small sample size (AICc) and then ranked by their weights (AICw; Burnham \& Anderson 2002). When the AICc of the candidate models differed by less than 2 units, we accepted the one with the lowest AICc as the best-fit model. We also calculated the evidence ratio between the presented models with the lowest AICc score and that of interest following the formula described in Burnham and Anderson (2002). For the joining order, we used a linear model approach to study the temporal link between topological ranks before departure (i.e. topological distance to goal area) and joining ranks during collective movements (R package lme4 v.1.1-21; Bates et al. 2015). We particularly looked at the evolution of the slope.

Before conducting analysis, all variables when included in the same model were screened for excessive correlations $(r>0.7)$ and collinearity (VIF $>10$, Dormann et al. 2013). All statistical analyses were performed in $\mathrm{R}$ version 3.6.1 ( $\mathrm{R}$ Core Team 2019). The 221 significance threshold was set at $\alpha=0.05$.

\section{Ethical Statement}

Our observations were carried out in full accordance with the ethical guidelines of our research institution and comply with the European legislation for animal welfare. This study 
226 has been conducted with the approval of our local ethical committee (reference: $227 \mathrm{AL} / 19 / 17 / 02 / 13)$.

\section{RESULTS}

\section{Evolution of predeparture behavioural patterns over time}

To assess variations during the 60 min period preceding departure, we compared various behaviours that were recorded every 5 minutes. We found that all analysed variables displayed significant changes over time (Figure 1). The number of goal-oriented individuals orientation: $\beta \pm \mathrm{SE}=0.019 \pm 0.002, \mathrm{t}_{584}=8.690, P<0.001$; GLMM, density: $\beta \pm \mathrm{SE}=0.008$

237 individuals decreased (LMM, dispersion: $\beta \pm \mathrm{SE}=-0.093 \pm 0.035, \mathrm{t}_{584}=-2.62, P=0.01$;

GLMM, group activity: $\beta \pm \mathrm{SE}=-0.019 \pm 0.003, \mathrm{t}_{584}=-5.638, P<0.001$, Figure 1$)$. Group

239 distance to goal area exhibited a quadratic relationship with time. Groups moved away from 240 the future destination before getting closer (LMM, distance to goal area, $\beta$ (time) $\pm \mathrm{SE}=$ $0.342 \pm 0.102, \mathrm{t}_{584}=-3.364, P<0.001, \beta\left(\mathrm{time}^{2}\right) \pm \mathrm{SE}=-0.004 \pm 0.002, \mathrm{t}_{584}=-2.595 P=$

242 0.01). This means that before departure and as the initiation is getting closer, individuals 243 become more active, oriented towards the future goal, reduce interindividual distances, 244 notably at the front of the group, and starts to move towards the goal.

\section{Comparison with control periods}

To assess if the above variables could indicate the imminence of a collective

247 movement, we compared predeparture periods with control periods. We found that similarly 248 to predeparture periods, the number of individuals oriented in the same direction increased 
over time during the control period (ANOVA, time x period type: Chisq $=2.577, P=0.11$ ) and within the same range (ANOVA, period type: Chisq $=0.0385, P=0.844$ ). Contrary to orientation, during control periods, time did not have the same effect on the number of individuals of inactive individuals (ANOVA: Chisq $=22.005, P<0.001$ ), which stayed constant (GLMM, time $\mathrm{x}$ period type: $\beta \pm \mathrm{SE}=0.024 \pm 0.005, P<0.001$; Figure 2). In addition, control periods were characterized, on average, by more inactive individuals than during predeparture periods (GLMM, period type: $\beta \pm \mathrm{SE}=0.77 \pm 0.24, \mathrm{t}_{537}=4.678, P<$ 0.001; Figure 2). The temporal pattern of group dispersion during control periods did not significantly differ from predeparture period (ANOVA, time $\mathrm{x}$ period type: Chisq $=0.0012, P$ $=0.97)$. However, dispersion in control periods was, on average, three-times higher than in predeparture periods suggesting a much lower group cohesion outside the context of collective movements (LMM, period type: $\beta \pm \mathrm{SE}=55.60 \pm 4.18, P<0.001$; Figure 2).

Finally, we also observed that during the predeparture period, the number of inactive individuals was significantly correlated to the number of individuals oriented in the same direction (Pearson $r=-0.15, P<0.001, N=678$ ) and the dispersion (Pearson $r=-0.13, P<$ $0.001, N=678$ ) contrary to the control periods (activity - orientation, Pearson $r=-0.03, P=$ $0.59, N=364$; activity - dispersion, Pearson $r=-0.09, P=0.16, N=470$ ).

\section{Predeparture behaviours predict the duration of the joining phase}

At initiation, multimodel inference showed that the best model to explain the duration of the joining phase (i.e. latency of the last follower) included dispersion alone (conditional average LMM: $\beta \pm \mathrm{SE}=0.740 \pm 0.141, z=5.172, p<0.001, \mathrm{RVI}=1$; Table S2). The more dispersed the individuals were, the longer it took for group members to follow (Figure 3a). At 25-30 min, the best model for the latency of the last follower included the density at the front alone (conditional average LMM: $\beta \pm \mathrm{SE}=-0.633 \pm 0.303, z=2.090, p=0.037$; relative 
274 variable importance, $\mathrm{RVI}=0.61$; Figure $3 \mathrm{~b}$, Table $\mathrm{S} 2$ ), meaning that the more individuals

275 gathered at the front during the predeparture period, the faster the joining phase was (Figure 276 3b). However, the two next models could not be excluded from the top-ranked models $277(\triangle \mathrm{AICc}<2)$ and therefore dispersion was also a good predictor of the duration of the joining 278 phase (conditional average LMM: $\beta \pm \mathrm{SE}=0.596 \pm 0.289, z=2.066, P=0.039 ; \mathrm{RVI}=0.60$; 279 Figure 3c, Table S2). At 55-60 min, the best model included the dispersion alone (conditional average LMM: $\beta \pm \mathrm{SE}=1.098 \pm 0.316, z=3.473, P<0.001, \mathrm{RVI}=0.98$; Table $\mathrm{S} 2$ ) meaning

281 that the more gathered the individuals were 60 minutes before departure, the faster the joining 282 phase was (Figure 3d). The three other variables, i.e. activity, orientation and distance to the goal area, were never included in the top-ranked models (activity RVI $<0.14$, orientation RVI $<0.06$, distance to the goal area RVI $<0.01)$.

\section{Spatial organization before departure predicts joining order}

We explored the evolution over time of spatial positions before departure as a function of the joining rank during collective movements. As shown by figure 4, there is a relationship between individual distances to the goal area at departure (LM [initiation] $\beta \pm \mathrm{SE}=0.46 \pm$ $\left.0.03, \mathrm{R}^{2}=0.21, P<0.0001\right)$ and up to $30-40$ minutes before departure (LM [30-35 min], $\beta \pm$

$\left.291 \mathrm{SE}=0.11 \pm 0.049, \mathrm{R}^{2}=0.01, P=0.027\right)$. The slope starts to increase around $30-35$ minutes before departure as well as the match between the linear regression and the mean value, 293 suggesting that the correlation between the spatial position and the future joining rank is 294 increasing over time (see Table S3 in supplemental material). This result also indicates that individual spatial position before departure is likely to predict how quickly a horse will join the ensuing collective movement. 


\section{DISCUSSION}

We found evidence that the dynamic of collective movements, from direction to 300 joining duration and order could be predicted by group behaviours exhibited before departure.

301 Our findings support the idea that decision-making begins well before departure. This 302 therefore means that the first departed individual is likely to be the mere catalyser of an 303 already-begun collective phenomenon and highlights the absolute necessity to look beyond 304 the timing of initiation to understand collective decision-making processes in animal societies.

\section{The specificity of pre-departure behavioural patterns}

307 During the hour prior departure, group behaviours changed over time. The number of inactive individuals progressively decreased, traducing a progressive arousal of the group (see Ward \& Zahavi 1973 for a definition of the "mood of the roost"). Simultaneously to this increase, the number of individuals gathered at the front and oriented towards the future collective movement increased over time. We also observed, a reduction of dispersion and distance to the future goal area before departure. The slight increase in group distance to the goal area before its decrease is likely to be due to the configuration of the environment the studied group lived in (i.e. limited space and destinations). Such gathering at the group periphery and synchronisation of behaviours before departure have been reported in many species (Boinski

\& Garber, 2000; Kummer, 1968a; Ramseyer, Boissy, Dumont, et al., 2009; Ramseyer,

317 Thierry, Boissy, et al., 2009; Strandburg-Peshkin et al., 2015) and were suggested as a preparation to collective movements. However, to be valid, this assumption needed to be tested by at least verifying that these modifications are not found outside the context of collective movements. Thanks to the comparison with control periods and more definitively

321 than previous studies, we can conclude on the specificity of predeparture periods. On one 322 hand, we found that the temporal increase in activity and cohesion was specific to 
323 predeparture periods. During control periods, the activity level stayed relatively constant and 324 group cohesion was much lower. Finally, we found that only during predeparture periods did 325 the number of goal-oriented individuals correlate with the number of inactive individuals and 326 the group dispersion. Therefore, the specificity of predeparture periods lies in the co327 occurrence of multiple patterns: a progressive decrease in the number of inactive individuals 328 associated with a low dispersion and a high degree of synchronization in terms of orientation. 329 Nevertheless, the differences between the indices characterizing the states of the group 330 (number of inactive individuals or dispersion) during the control and pre-departure phase raise 331 the question of the temporal evolution of these indices. For example, concerning the 332 dispersion, two extreme hypotheses can be formulated: a monotonic or a sudden decrease 333 when the group passes from the state observed during the control period to the pre-departure 334 period. An abrupt decrease would suggest that the adoption of a pre-departure configuration is 335 itself a social phenomenon (e.g. governed by mimetism; Sumpter, 2010). This dynamic 336 towards the pre-departure also raises the question of links between the pre-departure state and 337 the probability of initiating a movement and its success : are these probabilities governed by 338 the same cause as that governing the adoption of the predeparture configuration or do they 339 depend on the state/configuration of the group? New observations are needed to decipher 340 between these different hypotheses.

341 On the other hand, we found that the temporal pattern of group orientation in pre-departure 342 period is not different from the observed patterns during control periods. Such pattern 343 indicates that individuals maintain their orientation over multiple time steps (i.e inertia). As a 344 consequence, the probability that orientations are identical decreases with time (i.e. as we 345 move away from the initiation period). Moreover, social species are known to respond to the 346 behaviours of group members, such as body posture and orientation, by adopting the same 347 behaviours themselves, a process known as social facilitation or allelomimetism (Clayton, 
1978; Conradt \& Roper, 2000; Deneubourg \& Goss, 1989). In herbivores, such synchronization has often been observed outside the context of collective movements 350 (Benham, 1982; Côté, Schaefer, \& Messier, 1997; Gautrais, Michelena, Sibbald, Bon, \& 351 Deneubourg, 2007; Rands, Muir, \& Terry, 2014; Stoye, Porter, \& Stamp Dawkins, 2012). 352 Therefore, during predeparture periods the increasing number of individuals oriented in the 353 same direction predicts the direction of a potential collective movement but not an impending 354 group departure. The absence of difference between the predeparture and the control periods, 355 both in terms of dynamics and magnitude, puts into perspective the interpretation of the 356 progressive orientation of group members before departure. Such phenomenon is often 357 viewed as a preparation if not a negotiation or a voting process (Kummer, 1968b; Ramos et 358 al., 2015; Ramseyer, Boissy, Dumont, et al., 2009; Ramseyer et al., 2008; Ramseyer, Thierry, 359 et al., 2009; Strandburg-Peshkin et al., 2015; Sueur et al., 2010) and the resulting dynamics as 360 the consequence of the degree of consensus before departure. However, in the absence of control, the causal relationship between the degree of common orientation before departure and recruitment during collective movements should be interpreted cautiously. Here our

363 results suggest that the choice of destination could result from the global dynamics rather than an a priori choice.

\section{Predeparture behaviours and joining dynamic}

Interestingly, the behaviours that were specific to the predeparture periods and could predict the imminence of a departure were not the ones that predicted the joining dynamic. Indeed, the cohesion of the group, i.e. dispersion and density at the front, was the only factor that had a significant impact on the duration of the joining process. Our results confirmed those of previous studies on dispersion and recruitment in primates (Leca et al., 2003; Sperber 
et al., 2019; Sueur \& Petit, 2008) and birds (Ramseyer et al., 2008) but partially matched

373 those in heifers and ewes (Ramseyer, Boissy, Dumont, et al., 2009; Ramseyer, Thierry, 374 Boissy, et al., 2009). In these latter studies, the authors found an effect of dispersion but also 375 of orientation and activity at different times. The methodological differences make the 376 comparison quite difficult since they analysed only collective movements that occurred when 377 the individuals were aggregated within a certain perimeter before departure.

We also showed that before departure individuals that were closer to the front and therefore to the future goal area joined the collective movement earlier. On one hand, the spatial position of individuals may affect their capacity to initiate as demonstrated by Dyer et al. (2009) in groups of humans. They showed that peripheral individuals were more likely to move freely away from the group than central individuals. On the other hand, the progressive movement of an individual towards the front of the group may act both as a conspicuous cue of motivation and help to recruit group members. Similar results have been reported in Przewalski horses (Bourjade et al., 2009) and other animal societies (Boinski \& Garber, 2000; Kummer, 1968a; Ramseyer, Boissy, Dumont, et al., 2009; Ramseyer, Thierry, et al., 2009;

387 Strandburg-Peshkin et al., 2015; Sueur et al., 2010). It has been suggested that front-to-back 388 positioning within animal groups can be the consequences of behavioural or motivational 389 differences between group members (Couzin, Krause, James, Ruxton, \& Franks, 2002). 390 Individual differences in activity level (Homing pigeons, Columbia livia, Pettit et al. 2015), 391 age (red-fronted lemurs, Eulemur rufifrons, Sperber et al. 2019), satiation (roach, Rutilus 392 rutilus, Krause 1993), dominance (Hemelrijk, 1998) or in social attraction (domestic horses, 393 Equus f. caballus Briard et al. 2015) have shown to explain patterns of positioning within the 394 group. In addition to motivational differences, social preferences and/or shared phenotypes 395 (e.g. phenotypic assortativity, Krause, James, Franks, \& Croft, 2014) could underlie such 396 spatial positioning and differences in reactivity to an individual's departure. Indeed, it has 
been shown in numerous social species that social preferences and phenotypic similarities effect on how individuals are spatially organized (Briard et al., 2015; Godde, Humbert, Côté, Réale, \& Whitehead, 2013) and how they influence one another (i.e. selective mimetism, Sueur, Petit, \& Deneubourg, 2009).

The effect of both group cohesion and spatial positioning before departure on the joining dynamic suggests that even in case of high synchronisation in terms of activity or orientation, interindividual distances greatly affect recruitment. As a consequence of spatial sorting and group cohesion, individuals differ in their neighbourhood size (i.e. how many conspecifics an individual interacts with, Farine et al. 2017), which could affect their propensity to react to the initiator departure. In our study, since the initiator is among the closest to the front, it also means that individuals far from the goal area are far from the initiator. Therefore, it is possible that in domestic horses, as in a flock of birds under attack by a peregrine falcon (Ballerini et al., 2008), the propagation of information (i.e. departure of the initiator) and the reaction of individuals depended on distances. Such nearest neighbour effect was also found to underlie spatial organisation during collective movement in wild primates (Farine et al., 2016; Sperber et al., 2019) and activity synchronisation in red deer (Rands et al. 2014). Interestingly, until now, such effect was only identified in dense and large groups of animals where one individual is unlikely to see all its conspecifics.

Many questions remain to be addressed concerning the exact rules that underpin decision-making processes during collective movements in domestic horses. First of all, we could not study the effect of predeparture behaviours on the number of followers as the majority of recorded events involved the entire group. However, in numerous species including horses (Bourjade et al., 2009; Krueger et al., 2014; Petit et al., 2009; Sueur \& Petit, 2008), individuals can fail to recruit any group member and often have to renounce to depart from the group. Using such unsuccessful departures as well as control periods that only differ 
422 from predeparture periods by one parameter (e.g. dispersion) would provide useful insights on

423 why an initiation succeeds or fails and help understand decision-making processes. Moreover,

424 although it is clear that interindividual distances are at stake, even in this small-scale system,

425 our study did not allow us to disentangle between motivational differences and local

426 information transmission. Indeed, we did not record enough events during which the initiator

427 was not the closest to the goal. Experiments with trained individuals that would depart from

428 the group following a cue (Gérard, Valenchon, Poulin, \& Petit, 2020; Pillot et al., 2010)

429 would allow recording a sufficient number of events where the initiator holds various spatial

430 position. It could then be determined which differences in motivation or local information

431 transmission are decisive. Finally, we had to rely on discrete data to study the dynamic of

432 predeparture behaviours. With the rise of technology (e.g. GPS collars, drones, automatic

433 tracking software), continuous data could be collected allowing more advanced statistical

434 analysis, which could help uncover new behavioural patterns.

\section{Conclusion}

We demonstrate that decision-making during collective movements is a continuous

438 process that starts before departure in domestic horses. The use of control periods, a first in

439 the context of collective movements and predeparture behaviours, highlights the specificity of

440 periods preceding collective movements and how animals communicate their willingness to

441 move to other group members. Moreover, we showed that a behaviour often presented as

442 preparatory, i.e. interindividual alignment, was not specific to predeparture and occurred just

443 as often in other contexts. Finally, our work suggests that similarly to dense and large groups,

444 interindividual distances are a key aspect of decision-making processes in small and loose groups. Taken together our results clearly emphasise the necessity to look beyond the event of 
446 initiation and to take into account the role of local interactions to catch the whole decision-

447 making processes during collective movements of group-living species.

448

\section{BIBLIOGRAPHY}

450 Alexander, R. D. (1974). The Evolution of Social Behavior. Annual Review of Ecology and Systematics, 5(171), 325-383. https://doi.org/10.1111/j.1365-294X.2011.05232.x

Altmann, J. (1974). Observational Study of Behavior: Sampling Methods. Behaviour, 49, 227-267. https://doi.org/10.1002/zamm.19730531271

Ballerini, M., Cabibbo, N., Candelier, R., Cavagna, a, Cisbani, E., Giardina, I., ... Zdravkovic, V. (2008). Interaction ruling animal collective behavior depends on topological rather than metric distance: evidence from a field study. Proceedings of the National Academy of Sciences of the United States of America, 105(4), 1232-1237. https://doi.org/10.1073/pnas.0711437105

Barton, K. (2019). MuMIn: Multi-Model Inference. R Package Version 1.43.6. https://cran.rproject.org/package=MuMIn

461

462

463

464

465

Bates, D., Mächler, M., Bolker, B. M., \& Walker, S. C. (2015). Fitting linear mixed-effects models using lme4. Journal of Statistical Software, 67(1), 1-48. https://doi.org/10.18637/jss.v067.i01

Benham, P. F. J. (1982). Synchronisation of behaviour in grazing cattle. Applied Animal Behaviour Science, 8, 403-404.

Boinski, S., \& Garber, P. A. (2000). On the move: how and why animals travel in groups. University of Chicago Press.

Bourjade, M., Thierry, B., Hausberger, M., \& Petit, O. (2015). Is Leadership a Reliable Concept in Animals? An Empirical Study in the Horse. Plos One, 10(5), e0126344. https://doi.org/10.1371/journal.pone.0126344 
471 Bourjade, M., Thierry, B., Maumy, M., \& Petit, O. (2009). Decision-Making in Przewalski

472

473

474

475

476

477

478

479

480

481

482

483

484

485

486

487

488

489

490

491

492

493

494

495

Horses (Equus ferus przewalskii) is Driven by the Ecological Contexts of Collective Movements. Ethology, 115(4), 321-330. https://doi.org/10.1111/j.14390310.2009.01614.x

Bousquet, C. A. H., Sumpter, D. J. T., \& Manser, M. B. (2011). Moving calls: A vocal mechanism underlying quorum decisions in cohesive groups. Proceedings of the Royal Society B: Biological Sciences, 278(1711), 1482-1488.

https://doi.org/10.1098/rspb.2010.1739

Briard, L., Deneubourg, J.-L., \& Petit, O. (2017). How stallions influence the dynamic of collective movements in two groups of domestic horses, from departure to arrival. Behavioural Processes, 142, 56-63. https://doi.org/10.1016/j.beproc.2017.05.014

Briard, L., Dorn, C., \& Petit, O. (2015). Personality and Affinities Play a Key Role in the Organisation of Collective Movements in a Group of Domestic Horses. Ethology, 121(9), 888-902. https://doi.org/10.1111/eth.12402

Burnham, K. P., \& Anderson, D. B. (2002). Model selection and multimodel inference: $a$ pratical information-theoretic approach (2nd edn). New-York: Springer-Verlag.

Caro, T. M., Roper, R., Young, M., \& Dank, G. R. (1979). Inter-observer reliability. Behaviour, (69), 303-315. https://doi.org/10.1163/156853979X00520

Clayton, D. A. (1978). Socially Facilitated Behavior. The Quarterly Review of Biology, 53(4), 373-392. https://doi.org/10.1086/410789

Conradt, L., \& Roper, T. J. (2000). Activity synchrony and social cohesion: A fission-fusion model. Proceedings of the Royal Society B: Biological Sciences, 267(1458), 2213-2218. https://doi.org/10.1098/rspb.2000.1271

Conradt, L., \& Roper, T. J. (2005). Consensus decision making in animals. Trends in Ecology and Evolution, 20(8), 449-456. https://doi.org/10.1016/j.tree.2005.05.008 
Côté, S. D., Schaefer, J. A., \& Messier, F. (1997). Time budgets and synchrony of activities in muskoxen: The influence of sex, age, and season. Canadian Journal of Zoology, 75(10), 1628-1635. https://doi.org/10.1139/z97-789

Couzin, I. D., Krause, J., James, R., Ruxton, G. D., \& Franks, N. R. (2002). Collective memory and spatial sorting in animal groups. Journal of Theoretical Biology, 218(1), 111. https://doi.org/10.1006/jtbi.2002.3065

Cozzi, A., Sighieri, C., Gazzano, A., Nicol, C. J., \& Baragli, P. (2010). Post-conflict friendly reunion in a permanent group of horses (Equus caballus). Behavioural Processes, 85(2), 185-190. https://doi.org/10.1016/j.beproc.2010.07.007

Danchin, E., Giraldeau, L.-A., \& Cézilly, F. (Eds.). (2007). Behavioral Ecology. Oxford: Oxford University Press.

de Schutter, G. (1997). Collective intelligence among unrelated: how to share collective benefits or what do gull do at night? In G. Theraulaz \& F. Spitz (Eds.), Autoorganisation et comportement (pp. 157-168). Hermes.

Deneubourg, J.-L., \& Goss, S. (1989). Collective patterns and decision-making. Ethology Ecology \& Evolution, (1), 295-311.

Dormann, C. F., Elith, J., Bacher, S., Buchmann, C., Carl, G., Carré, G., ... Lautenbach, S. (2013). Collinearity: A review of methods to deal with it and a simulation study evaluating their performance. Ecography, 36(February 2012), 027-046. https://doi.org/10.1111/j.1600-0587.2012.07348.x

Dyer, J. R. G., Johansson, A., Helbing, D., Couzin, I. D., \& Krause, J. (2009). Leadership, consensus decision making and collective behaviour in humans. Proceedings of the Royal Society B: Biological Sciences, 364, 781-789. https://doi.org/10.1098/rstb.2008.0233

Farine, D. R., Strandburg-Peshkin, A., Berger-Wolf, T. Y., Ziebart, B., Brugere, I., Li, J., \& 
Crofoot, M. C. (2016). Both nearest neighbours and long-term affiliates predict individual locations during collective movement in wild baboons. Scientific Reports, 6 . https://doi.org/10.1038/srep27704

524

525

Farine, D. R., Strandburg-Peshkin, A., Couzin, I. D., Berger-Wolf, T. Y., \& Crofoot, M. C. (2017). Individual variation in local interaction rules can explain emergent patterns of spatial organization in wild baboons. Proceedings of the Royal Society B: Biological Sciences, 284(1853). https://doi.org/10.1098/rspb.2016.2243

Gautrais, J., Michelena, P., Sibbald, A., Bon, R., \& Deneubourg, J.-L. (2007). Allelomimetic synchronization in Merino sheep. Animal Behaviour, 74, 1443-1454. https://doi.org/10.1016/j.anbehav.2007.02.020

Gérard, C., Valenchon, M., Poulin, N., \& Petit, O. (2020). How does the expressiveness of leaders affect followership in domestic horses (Equus ferus caballus)? Animal Cognition, 23(3), 559-569. https://doi.org/10.1007/s10071-020-01361-8

Godde, S., Humbert, L., Côté, S. D., Réale, D., \& Whitehead, H. (2013). Correcting for the impact of gregariousness in social network analyses. Animal Behaviour, 85(3), 553-558. https://doi.org/10.1016/j.anbehav.2012.12.010

Hemelrijk, C. K. (1998). Spatial centrality of dominants without positional preference. Artificial Life, Vol. 6, 307-315.

King, A. J., Douglas, C. M. S., Huchard, E., Isaac, N. J. B., \& Cowlishaw, G. (2008). Dominance and Affiliation Mediate Despotism in a Social Primate. Current Biology, 18(23), 1833-1838. https://doi.org/10.1016/j.cub.2008.10.048

King, A. J., Johnson, D. D. P., \& Van Vugt, M. (2009, October). The Origins and Evolution of Leadership. Current Biology. Elsevier. https://doi.org/10.1016/j.cub.2009.07.027

Krause, J. (1993). Oecologia shoal of roach (Rutilus rutilus) and chub (Leuciscus cephalus): a field study. Oecologia, 93, 356-359. 
546 Krause, J., James, R., Franks, D., \& Croft, D. (Eds.). (2014). Animal Social Networks. Oxford

547 University Press. https://doi.org/10.1093/acprof:oso/9780199679041.001.0001

548 Krueger, K., Flauger, B., Farmer, K., \& Hemelrijk, C. K. (2014). Movement initiation in

549 groups of feral horses. Behavioural Processes, 103, 91-101.

$550 \quad$ https://doi.org/10.1016/j.beproc.2013.10.007

551 Kummer, H. (1968a). Social organization of hamadryas baboons: a field study (1st Editio).

552 Chicago: The University of Chicago Press.

553 Kummer, H. (1968b). Social Organization of Hamadryas Baboons. Chicago: University of 554 Chicago Press.

555 Leca, J. B., Fornasieri, I., \& Petit, O. (2002). Aggression and reconciliation in Cebus 556 capucinus. International Journal of Primatology, 23(5), 979-998.

557 https://doi.org/10.1023/A:1019641830918

558 Leca, J. B., Gunst, N., Thierry, B., \& Petit, O. (2003). Distributed leadership in semifree559 ranging white-faced capuchin monkeys. Animal Behaviour, 66(6), 1045-1052. 560 https://doi.org/10.1006/anbe.2003.2276

561 O’Connell-Rodwell, C. E., Wood, J. D., Wyman, M., Redfield, S., Puria, S., \& Hart, L. A. 562 (2012). Antiphonal vocal bouts associated with departures in free-ranging African 563 elephant family groups (Loxodonta africana). Bioacoustics, 21(3), 215-224.

$564 \quad$ https://doi.org/10.1080/09524622.2012.686166

565 Petit, O., \& Bon, R. (2010). Decision-making processes: the case of collective movements. 566 Behavioural Processes, 84(3), 635-647. https://doi.org/10.1016/j.beproc.2010.04.009

567 Petit, O., Gautrais, J., Leca, J. B., Theraulaz, G., \& Deneubourg, J. L. (2009). Collective 568 decision-making in white-faced capuchin monkeys. Proceedings of the Royal Society B: 569 Biological Sciences, 276(1672), 3495-3503. https://doi.org/10.1098/rspb.2009.0983

570 Pettit, B., Ákos, Z., Vicsek, T., \& Biro, D. (2015). Speed determines leadership and 
leadership determines learning during pigeon flocking. Current Biology, 25(23), 31323137. https://doi.org/10.1016/j.cub.2015.10.044

573 Pillot, M. H., Gautrais, J., Gouello, J., Michelena, P., sibbald, A., \& Bon, R. (2010). Moving 574 together: Incidental leaders and naïve followers. Behavioural Processes, 83(3), 235-241. $575 \quad$ https://doi.org/10.1016/j.beproc.2009.11.006

576 Pinheiro J., Bates D., DebRoy S., Sarkar D. \& R Core Team (2019). nlme: Linear and 577 Nonlinear Mixed Effects Models. R package version 3.1-140, https://CRAN.R$578 \quad$ project.org/package $=$ nlme.

579 Pyritz, L. W., King, A. J., Sueur, C., \& Fichtel, C. (2011). Reaching a Consensus:

580 Terminology and Concepts Used in Coordination and Decision-Making Research.

581 International Journal of Primatology, 32(6), 1268-1278. https://doi.org/10.1007/s10764$582 \quad 011-9524-9$

583 R Core Team. (2015). R: A language and environment for statistical computing. $R$ 584 Foundation for Statistical Computing, Vienna, Austria, URL http://www.R-project.org/.

Ramos, A., Petit, O., Longour, P., Pasquaretta, C., \& Sueur, C. (2015). Collective decision making during group movements in European bison, Bison bonasus. Animal Behaviour, 109(November), 149-160. https://doi.org/10.1016/j.anbehav.2015.08.016

Ramseyer, A., Boissy, A., Dumont, B., \& Thierry, B. (2009). Decision making in group departures of sheep is a continuous process. Animal Behaviour, 78(1), 71-78. https://doi.org/10.1016/j.anbehav.2009.03.017

Ramseyer, A., Petit, O., \& Thierry, B. (2008). Patterns of group movements in juvenile domestic geese. Journal of Ethology, 27(3), 369-375. https://doi.org/10.1007/s10164008-0128-6

Ramseyer, A., Thierry, B., Boissy, A., \& Dumont, B. (2009). Decision-making processes in group departures of cattle. Ethology, 115, 948-957. https://doi.org/10.1111/j.1439- 
597 Rands, S. A., Muir, H., \& Terry, N. L. (2014). Red deer synchronise their activity with close 598 neighbours. PeerJ, 2, e344. https://doi.org/10.7717/peerj.344

599 Schaller, G. E. (1963). The mountain gorilla: Ecology and behavior. Oxford: The University 600 of Chicago Press.

601 Seltmann, A., Majolo, B., Schülke, O., \& Ostner, J. (2013). The Organization of Collective 602 Group Movements in Wild Barbary Macaques (Macaca sylvanus): Social Structure 603 Drives Processes of Group Coordination in Macaques. PLoS ONE, 8(6).

604 https://doi.org/10.1371/journal.pone.0067285

605

606

607

608

609

610

611

612

613

614

615

616

617

618

619

620

Sperber, A. L., Kappeler, P. M., \& Fichtel, C. (2019). Should i stay or should i go? Individual movement decisions during group departures in red-fronted lemurs. Royal Society Open Science, 6(3). https://doi.org/10.1098/rsos.180991

Stewart, K. J., \& Harcourt, A. H. (1994). Gorillas' vocalizations during rest periods: signals of impending departure. Behaviour, 130, 1-2.

Stoye, S., Porter, M. A., \& Stamp Dawkins, M. (2012). Synchronized lying in cattle in relation to time of day. Livestock Science, 149(1-2), 70-73. https://doi.org/10.1016/j.livsci.2012.06.028

Strandburg-Peshkin, A., Farine, D. R., Couzin, I. D., \& Crofoot, M. C. (2015). Shared decision-making drives collective movement in wild baboons. Science, 348(6241), 1-5.

Sueur, C., Deneubourg, J.-L., \& Petit, O. (2010). Sequence of quorums during collective decision making in macaques. Behavioral Ecology and Sociobiology, 64(11), 18751885. https://doi.org/10.1007/s00265-010-0999-8

Sueur, C., \& Petit, O. (2008). Shared or unshared consensus decision in macaques? Behavioural Processes, 78(1), 84-92. https://doi.org/10.1016/j.beproc.2008.01.004

Sueur, C., Petit, O., \& Deneubourg, J.-L. (2009). Selective mimetism at departure in 

collective movements of Macaca tonkeana : an experimental and theoretical approach. Animal Behaviour, 78, 1087-1095. https://doi.org/10.1016/j.anbehav.2009.07.029

623 Sumpter, D. J. (2010). Collective Animal Behaviour. Princeton University Press.

624 Tyler, S. J. (1972). The behaviour and social organization of the new forest ponies. Animal 625 Behaviour, 5(PART 2), 87-196. https://doi.org/10.1016/0003-3472(72)90003-6

626 Venables, W., \& Ripley, B. (2002). Modern Applied Statistics Using S. New York, USA: $627 \quad$ Springer.

628 Walker, R. H., King, A. J., McNutt, J. W., \& Jordan, N. R. (2017). Sneeze to leave: African 629 wild dogs (Lycaon pictus) use variable quorum thresholds facilitated by sneezes in 630 collective decisions. Proceedings of the Royal Society B: Biological Sciences, $631284(1862)$. https://doi.org/10.1098/rspb.2017.0347

632 Ward, A. J. W., Herbert-Read, J. E., Jordan, L. A., James, R., Krause, J., Ma, Q., ... Morrell, 633 L. J. (2013). Initiators, leaders, and recruitment mechanisms in the collective movements 634 of damselfish. American Naturalist, 181(6), 748-760. https://doi.org/10.1086/670242 635 Ward, P., \& Zahavi, A. (1973). The importance of certain assemblages of birds as 636 “information-centres” for food-finding. Ibis, (115), 517-534.

637 Waring, G. H. (2003). Horse behavior. William Andrew. 638 639

\section{TABLES}

Table 1 - Behavioural variables of the predeparture period used in analyses

\begin{tabular}{ll}
\hline Behaviours & Definition \\
\hline Group activity & Number of inactive individuals i.e. at rest, standing with a flexed foot or \\
& recumbent.
\end{tabular}


Group orientation Number of individuals oriented in the direction of the movement defined as the bisecting line of $45^{\circ}$ sector. For the control period, the referential direction was the direction chosen by the majority of individuals within the time category 0 and was subsequently used in the preceding time categories.

Group distance to Distance in meters between the arrival area and the barycentre of the group the goal area based on xy-coordinates.

Group dispersion Mean distance in meters between each horse and the barycentre of the group base on the xy-coordinates, i.e. $D=\sum \sqrt{ }\left[\left(X_{i}-X_{b c}\right)^{2}+\left(Y_{i}-Y_{b c}\right)^{2}\right] / N$

Density at the front Number of individuals within 10m away from the front of the group. The front is of the group defined by the distance of the closest individual to the arrival area

\section{FIGURE LEGENDS}

Figure 1 - Patterns of (a) orientation, (b) density at the group front, (c) dispersion, (d) distance to goal area and (e) activity, in the 60 min period preceding departures of the entire group.

648 The mean and standard errors are represented for each type of behaviour and time categories. The red 649 line represents the linear (orientation, front density, dispersion and activity) and quadratic regression 650 (distance to goal). From $0 \min$ to $60 \min , N=93, N=63, N=73, N=63, N=55, N=54, N=47, N$ $=43, N=35, N=36, N=30$ and $N=32$.

653 Figure 2 - Comparison of the evolution of group behaviour, (a) orientation, (b) activity and (c) 654 dispersion, between predeparture periods (dark grey) and control periods (light grey).

655 Graphs represent the mean and standard errors for each type of behaviour and time categories. From 0 $656 \min$ to $60 \mathrm{~min}$, control periods, $N=101, N=103, N=104, N=92$ and $N=70$. From 0 min to 60 $657 \min$, predeparture periods, $N=93, N=63, N=54, N=35$ and $N=32$. 
659 Figure 3 - Relationships between the joining latency of the last follower and (a) the dispersion at 660 departure, (b) the density at the group front and (c) the dispersion, 30 minutes before departure, (d) the 661 dispersion 60 minutes before departure. Solid lines of corresponding colours show the line of best fit 662 in the linear mixed-effects model and shade areas standard errors.

663

664 Figure 4 - Temporal evolution of the relationship between spatial position before departure and 665 joining rank during collective movements.

666 Each window corresponds to a time category (from $t=0 \mathrm{~min}$, the initiation, to $t=55-60 \mathrm{~min}$ ).

667 Boxplots represent the distribution of topological distances to the goal area as a function of the future 668 joining rank (e.g. joining rank 1 is the initiator, joining rank 2 the first follower, etc.). The thick curvy 669 black line represents the mean topological rank for each joining rank and the thin straight black line 670 represents the linear regression.

671

672 


\section{ACKNOWLEDGEMENTS}

We would like to thank Brigitte Laurent for giving us access to her horses. We are also grateful to our trainees Valentin Julien, Tristan Juette, Sarah Fernique and Amandine Ramos for their valuable help with data collection. Data were collected during L.B.'s doctorate at the Department of Ecophysiology, Physiology and Ethology (CNRS - UdS, UMR 7178, Strasbourg, France) and Unit of Social Ecology (Free University of Brussel, Belgium)

\section{FUNDING}

This work was financially supported by the French Ministry of Higher Education and Research, the Foundation des Treilles, David et Alice van Buuren, de Meurs-François and Groupement de Recherche en Ethologie 2822 (to LB).

\section{AUTHORS' CONTRIBUTIONS}

$L B$ collected field data, participated in the design of the study, carried out the statistical analysis and drafted the manuscript; OP and JLD supervised and coordinated the study, participated in the data analysis and helped draft the manuscript. All authors gave final approval for publication. 

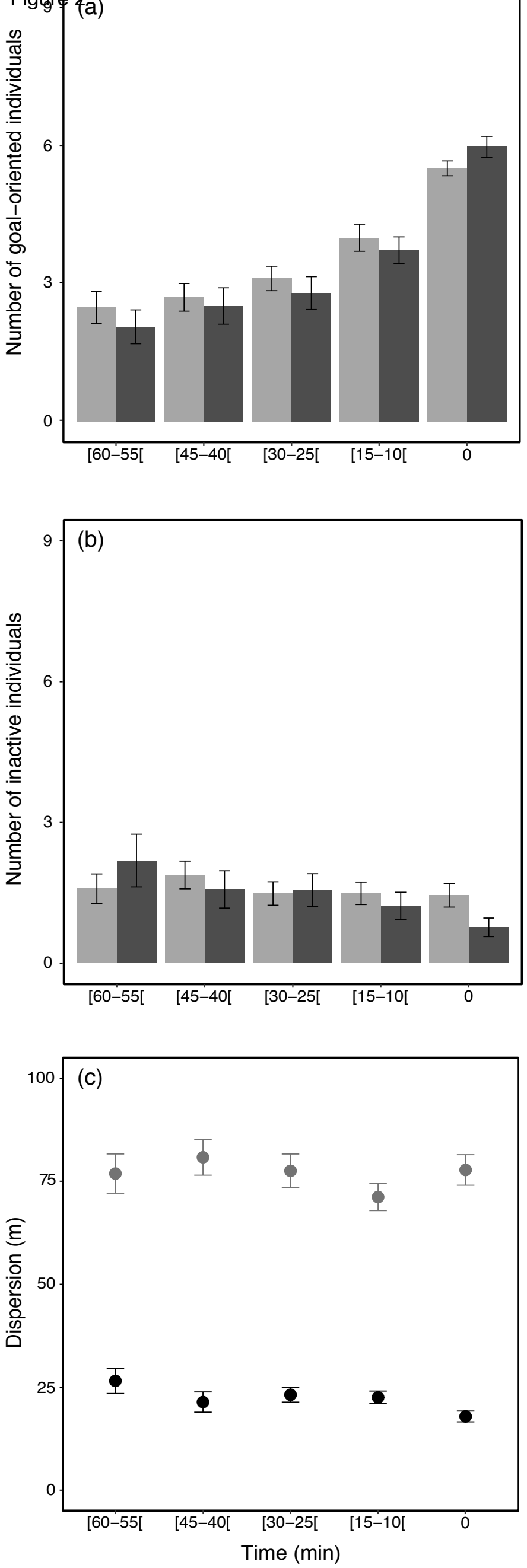

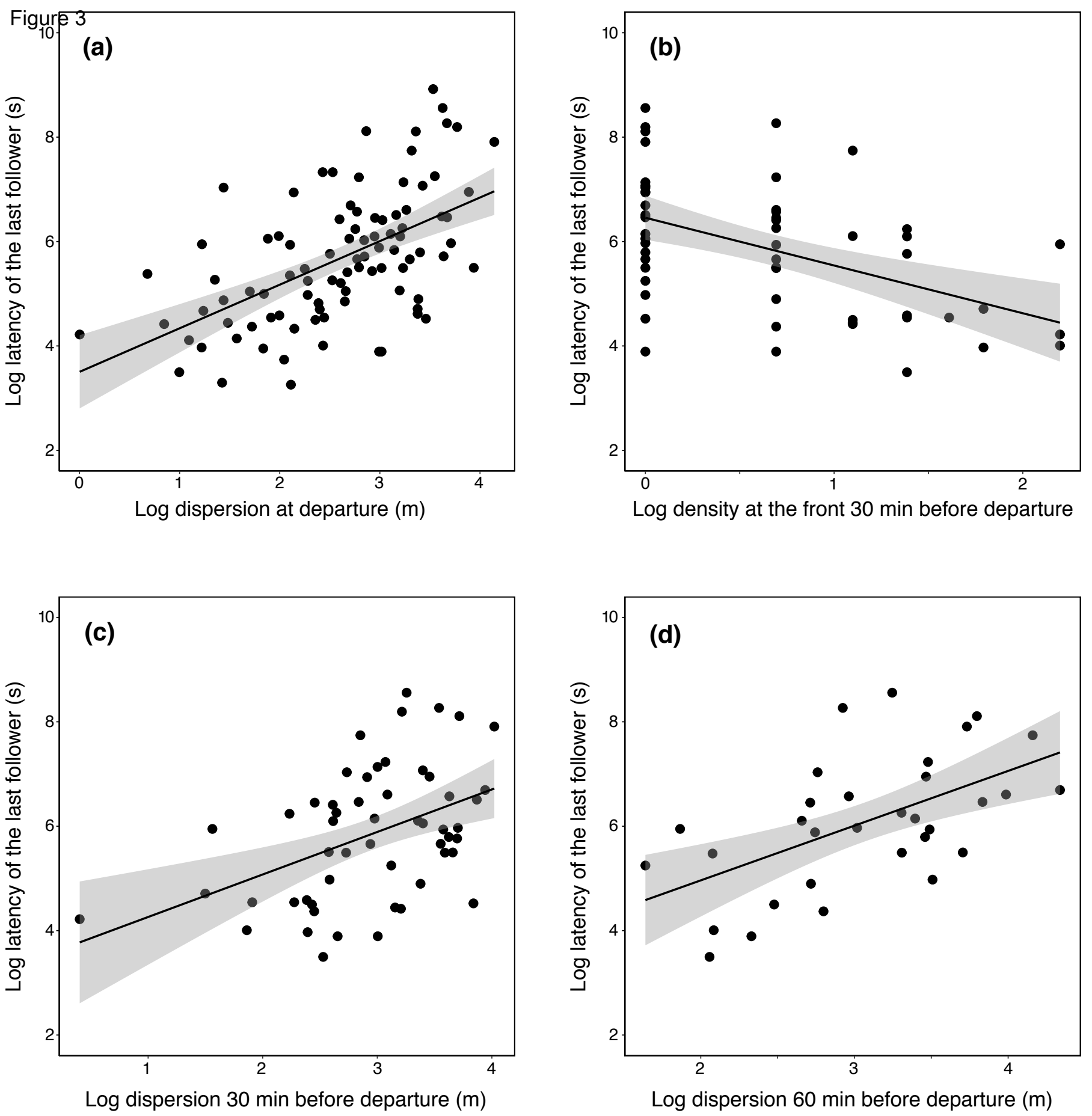

Log dispersion 30 min before departure $(\mathrm{m})$ 


\section{Supplementary material}

Table S1 - Table reporting characteristics of each horse (group, breed, age)

\begin{tabular}{|c|c|c|c|}
\hline Group & Individual & Breed & Age (yr) \\
\hline & $\mathrm{Gr}$ & WP & 18 \\
\hline & $\mathrm{Ha}$ & $\mathrm{AB}$ & 17 \\
\hline & Is & WP & 16 \\
\hline & $\mathrm{Ju}$ & WP & 15 \\
\hline \multirow[t]{9}{*}{1} & $\mathrm{Li}$ & $\mathrm{AB}$ & 13 \\
\hline & Ma & PT & 12 \\
\hline & $\mathrm{Pa}$ & $\mathrm{AB}$ & 9 \\
\hline & $\mathrm{Su}$ & $\mathrm{PT}$ & 28 \\
\hline & $\mathrm{Ve}$ & $\mathrm{PT}$ & 27 \\
\hline & $\operatorname{Re}$ & FB & 7 \\
\hline & $\mathrm{Ti}$ & $\mathrm{PT}$ & 5 \\
\hline & $\mathrm{Tq}$ & FB & 5 \\
\hline & $\mathrm{Tx}$ & HT & 22 \\
\hline \multirow[t]{5}{*}{2} & $\mathrm{Uc}$ & $\mathrm{PT}$ & 4 \\
\hline & Ul & FB & 4 \\
\hline & Vk & FB & 3 \\
\hline & Vo & FB & 3 \\
\hline & Vt & HT & 3 \\
\hline
\end{tabular}

Breeds: $N F=$ New Forest; $W P=$ Welsh Pony; $F B=$ French Breed; $P T=$ Pony

Type; $H T=$ Horse Type; $A B=$ Arabian Breed 
Table S2 - Model selections with Akaike's information criterion corrected for small sample size (AICc) for the models used to examine the influence of predeparture behaviours on the duration of the joining phase (i.e. latency of the last follower). The degree of freedom (df), the weights (wi) and the evidence ratio (E/R) for each model are also indicated. The full model comprised dispersion, group activity, group orientation, front density and distance to the goal area as independent variables. The identity of the the initiator was used as a random factor. Models in bold represent the best-fit models for each dependent variable $(\triangle \mathrm{AICc}<2)$.

\begin{tabular}{|c|c|c|c|c|c|}
\hline Model terms & $\mathrm{df}$ & $\mathrm{AICc}$ & $\triangle \mathrm{AICc}$ & wi & $\mathrm{E} / \mathrm{R}$ \\
\hline \multicolumn{6}{|l|}{ At departure } \\
\hline Full model & 8 & 309.7 & 29.51 & 0 & $\infty$ \\
\hline Log (dispersion) & 4 & 280.2 & $\mathbf{0}$ & 0.785 & 1 \\
\hline $\log ($ dispersion $)+\log ($ front density $)$ & 5 & 284.0 & 3.77 & 0.119 & 6.60 \\
\hline Null model (intercept only) & 3 & 300.1 & 19.83 & 0 & $\infty$ \\
\hline \multicolumn{6}{|l|}{30 min before departure } \\
\hline Full model & 8 & 190.0 & 19.05 & 0 & $\infty$ \\
\hline Log (front density) & 4 & 170.9 & $\mathbf{0}$ & 0.341 & 1 \\
\hline Log (dispersion) & 4 & 171.2 & $\mathbf{0 . 3 0}$ & 0.294 & 1.16 \\
\hline $\log$ (front density) + Log (dispersion) & 5 & 172.3 & 1.32 & 0.071 & 4.80 \\
\hline Null model (intercept only) & 3 & 178.0 & 7.01 & 0.010 & 34.1 \\
\hline \multicolumn{6}{|l|}{60 min before departure } \\
\hline Full model & 8 & 131.3 & 27.87 & 0 & $\infty$ \\
\hline Log (dispersion) & 4 & 103.4 & $\mathbf{0}$ & 0.700 & 1 \\
\hline $\log ($ dispersion $)+\log ($ front density $)$ & 5 & 106.3 & 2.91 & 0.164 & 4.27 \\
\hline Null model (intercept only) & 3 & 112.3 & 8.88 & 0.008 & 87.5 \\
\hline
\end{tabular}




\begin{tabular}{|c|c|c|c|c|}
\hline Time categories & Estimate (slope) & SE & $\mathbf{R}^{2}$ & p-value \\
\hline Initiation & 0.459 & 0.031 & 0.21 & $<0.0001$ \\
\hline $0-5 \mathrm{~min}$ & 0.175 & 0.041 & 0.029 & $<0.0001$ \\
\hline $5-10 \min$ & 0.259 & 0.038 & 0.066 & $<0.0001$ \\
\hline $10-15 \min$ & 0.161 & 0.041 & 0.024 & \begin{tabular}{|l|}
0.0001 \\
\end{tabular} \\
\hline $15-20 \min$ & 0.146 & 0.044 & 0.019 & 0.0011 \\
\hline $20-25 \min$ & 0.163 & 0.045 & 0.025 & \begin{tabular}{|l|}
0.0003 \\
\end{tabular} \\
\hline $25-30 \min$ & 0.158 & 0.045 & 0.023 & 0.0005 \\
\hline $30-35 \min$ & 0.108 & 0.049 & \begin{tabular}{|l|}
0.009 \\
\end{tabular} & \begin{tabular}{|l|}
0.0269 \\
\end{tabular} \\
\hline $35-40 \min$ & 0.085 & 0.051 & 0.005 & 0.0933 \\
\hline $40-45 \min$ & -0.025 & 0.056 & -0.003 & 0.6600 \\
\hline $45-50 \mathrm{~min}$ & 0.049 & 0.056 & -0.007 & 0.3806 \\
\hline $50-55 \mathrm{~min}$ & 0.083 & 0.061 & 0.003 & 0.1724 \\
\hline $55-60 \min$ & 0.064 & 0.059 & 0.007 & 0.2730 \\
\hline
\end{tabular}

